\title{
Moderating Effect of Speed Desire Frustration on the Relationship between Driving Stress and Coping Behavior on Traffic Accident Risk"
}

\author{
Soon Yeol Lee ${ }^{\dagger}$ \\ Road Traffic Authority
}

\author{
Soon Chul Lee
}

Chungbuk National University

The present study was conducted to determine the effects of driving stress on traffic accident risk. Specifically, the study verified whether a driver's speed desire frustration plays a control role in the relations between driving stress and traffic accident risk. As a result, a driver's speed desire frustration level played a control role in the relation between driving stress and traffic accident risk. This indicates that a driver's speed desire frustration level change driving stress sensitivities, thus changing the effects of selecting coping behavior types and causing differences in total traffic accident risk. The results show that the mere concentration on driving stress management cannot sufficiently lower the traffic accident risks caused by driving stress. This is because driving stress have indirect influences on traffic accident risk. Hence, it will be necessary to seek how to reduce driving stress and control coping behavior types in order to lower the traffic accidents risk by the stress.

Key words : Driving stress; Speed desire frustration; Traffic accident risk; moderating effect

* This study had been published as a part of the corresponding author's doctoral dissertation of Chungbuk National University, Republic of Korea in 2011.

† Corresponding Author : Soon Yeol Lee, Road Traffic Authority, 160 Wangsimni-gil, Jung-gu, Seoul, Republic of Korea, yeolsun@hanmail.net 


\section{Introduction}

In the study of the relation between stress and coping with stress behaviors; or between behavioral problems and thoughts, the search for the third cause of change which alters the structural relations or plays adjustable functions among the present causes, becomes an important subject of the study. For example, in the study of both job stress and life stress:

Availability, resilience and the kind of supporters or personality characteristics have been considered as the causes of functions for adjusting (Block \& Kremen, 1996; Hoare, 2001; Parker, Reason, \& Manstead, 1995).

\section{The Relationship between Driving Stress and Coping Behavior on Traffic Accident Risk}

Accidents encountered in traffic are caused by the mechanical manipulation that interlocks with lapses, mistakes and violations drivers commit towards traffic regulations. Therefore, these are treated as industrial accidents as well as traffic accidents. At the first stage, the occurrence of traffic accidents had been attributed to lack of mechanical problems and poor road conditions as well as safety facilities were included later as the cause. Several psychological instabilities were added further, such as behavioral aspects of the driver, styles of perception, individual differences in the maintenance of load, and the driver's attention span. Attributing human factors as the cause of the occurrences of traffic accidents have gradually been increased ever since. It has been reported in the Rumar's study of 1985 that human factors are the primary causes of traffic accidents $95 \%$ in the United Kingdom and 94\% in the United States.

In this context, we should carefully consider driving stress with the factors of drivers' psychological characteristics. Stress is defined as an imbalance of the individual ability to adapt to the environmental demands (Lazarus \& Folkman, 1986), and it has emerged as an important topic in the research to reduce the risk and prevent the disastrous accidents. Excessive stress can work as a crucial factor to cause negative emotions arising and increasing aggressive behavior thereby leading to accidents (Westeman \& Haigney, 2000).

Driving stress can be defined as an imbalance of ability to adapt to the manner of driving on the road, as the incident and accident arise so does stress, thereby resulting in a terrible accident (Lee \& Lee, 2008). Driving a motor vehicle triggers stress on the human body and mind, thus increasing chances of inappropriate driving, risks of recklessness. Hence, studying the effect of driving stress on the traffic accident is considered an essential topic for research that may serve as preventing road jeopardy for drivers and even pedestrians (Kontogiannis, 2006).

In order to view the study on the impact of 
stress towards the problematic behavior and harsh accidents comprehensively, the impact that indirectly relates to stress-coping behavior should be carefully considered along with its direc impact (Lee \& Lee, 2009a). This is because human beings are not passive accepting stress unilaterally but as an active existence which has power to actively react, adjust and overcome (Lazarus \& Folkman, 1991). Active responses to the adaptive efforts and stress factors are collectively referred to as coping. The driver responds in his own way even during the occurrence of driving stress. The risk of traffic accidents may vary depending on the driver's choices decision-making (Lee \& Lee, 2009a; 2010).

It will be reasonable for coping behaviors to be assumed as independent variables caused by the occurrence of driving stress, as well as dependent variables impacted by the accident risks. Therefore, it can be anticipated that a coping behavior in relation to the driving stress and traffic accident risks takes an intermediary role depending on the order of occurrences. According to the Lee and Lee's study (2008; 2009a), driving stress turns a coping behavioral pattern negative and increases the risk of traffic accidents. Thus, analyzing the expected variables that strengthens the relationship of driving stress and coping behaviors influencing traffic accidents negatively, and verifying the effects can become an important topic for research when it comes to reducing risks of traffic accidents.
The relationship among accidents, problematic behavior and stress may be altered or controlled by the third variable. For example, according to other studies on job stress or life stress, stress is regulated by the individual ability of recovery, presence of supporting group, and individual personality traits (Desmond, Matthews, \& Bush, 2001). It is important to study the third variable and how it can work as a moderating factor on the relationship between driving stress and coping behavioral patterns on the risks of traffic accidents. This research focuses on speed desire frustration, as the variable which raises stress responsiveness of a driver and how it gives a negative effect on coping behavioral patterns.

\section{Speed Desire Frustration}

Many studies have proven that either the driver's intention to pursue speed or speeding inclination controls a mental and perceptual process on driving behaviors (Lee \& Lee, 2009b; Stradling, Meadows, \& Beatty, 2004). A human's desire to move with high speed is intrinsic in the use of automobiles. It is acknowledged that a driver's desire for speed or pursuit of speed inclination is a general phenomenon; when a person is on the wheel (Cooper, 1996). A driver's desire for speed can cause trouble, especially when it is unfulfilled as well as when it results in unwanted outcomes.

In the United States, telephone surveys show that more than two-thirds of the drivers 
responded to be speeding over the limit while the remaining one-third are the ones driving within the right speed limit. Most of the time; the speed increases whenever a car is used for commercial purposes rather than one used for private purposes (Williams, Kyrychenko, \& Retting, 2006).

In the survey of driver awareness in Korea, $70 \%$ of all drivers were claimed to have overspeed once a week; and $60 \%$ of them have experienced it on most of the streets. In the same study, $53.7 \%$ of all drivers almost exceeded the speed limit (Korea Road Traffic Authority, 1998). The driver's desire to speed can be a problem whether he is to speed off excessively or not.

With a theory of desire frustration by Berkowitz and Lepage (1967), it explains the phenomenon of increasing aggressiveness when a human's frustration is agitated. Agitated frustration arises when a person fails to reach his goals, which causes aggressive driving, in other words, one of the major factors for aggressive behavior while driving is the influence of the surrounding which lead to an accident-prone situation.

The first factor of a provoked misbehavior is a physical or an environmental deficiency, which prevents drivers from fulfilling their attempts. This can be a driving situation revealing a form of wrong handling of speed in terms of environmental deficiency. In his traffic environment, a driver tries to maintain an evenly risk level. Therefore, on a straight road, in a good condition without any obstacles, he accelerates the driving speed, while on steep curves or slippery roads he reduces the driving speed, which is similar on snowy or icy roads. Like this a driver experiences a mishandled behavior when he has to drive with a lower speed than his speed of expectation, for his cognition of risk increases in the physical and environmental deficiency of a driving environment (Lee \& Lee, 2009b). The second reason for mishandled behavior is the obstacles which prevent drivers from accomplishing goals. Those obstacles can become a target of an emotional attack. In terms of a driving environment, those obstacles are movements of other automobiles. High traffic density and other vehicles which try to run ahead hinder other vehicles from moving forward. In this situation, other drivers can become targets of our emotional attack for we experience a desire frustration on speed because of environmental obstacles (Lee \& Lee, 2009b).

Frustration of desire can work as a crucial factor to cause negative emotions from arising and increasing of aggressive behavior leading to recklessness (Williams et al., 2006).

\section{Moderating Effect of Speed Desire Frustration}

If we combine a pursuit of speed inclination and a theory of desire frustration, one can 
anticipate those speed-desire-frustrating situations leading a driver into negative emotions and increase of aggressive driving inclination, which results in the increase of traffic accident risks. Lee and Lee (2009b) have disclosed that driving stress of drivers with high speed desire frustration increases dramatically. Thus, high speed desire frustration strengthens the degree of increasing that said driving stress raising negative coping behavior. Lee and Lee (2009b) analyzed how the speed desire frustration affects driving stress. Desire frustration on speed increases the level of driving stress. The higher one's desire frustration is on speed, the higher the risk of driving stress and a possibility of negative reactions. This indicates that a driver's speeddesire-frustration can change the responsiveness of driving stress. Also, Underwood, Chapman, Wright, \& Crundall (1999) reported that speed desire frustrating situations, such as traffic jams, increase the degree of stress, and the rise of these stress and frustration bring up worse merging into lanes, aggressive lane shift, dangerous driving attempts, and breaking traffic rules as well as traffic accidents. That is, a driver's frustration in terms of speed desire amplifies negative emotions and increases retrogressive traffic behavior, which threaten traffic safety.

\section{Aims}

These results will show that a driver's speed desire frustration level has a negative influence on responsiveness to driving stress and driving behaviors so it has a possibility of working as a controlling variable, which play vital roles in preventing traffic accidents. Therefore, we need to carefully observe what kind of change the speed desire frustration will bring in the relation between driving stress and a coping behavioral pattern, which has an influence on traffic accident risks.

Based on the theoretical and empirical background presented above, our predictions are as follows: Speed desire frustration will moderate that driving stress and coping behavior effect on traffic accident risks.

\section{Method}

\section{Participants}

The research for this study has been performed in the Road Traffic Authority education centers of the Republic of Korea and also in the Driving License Test Centers of the Republic of Korea, having had surveyed 518 drivers who had a practical driving experience. Of all the respondents, 26 were disapproved as they were found to respond insincerely without even thinking about asking questions to measure the sincerity of their responses and 492 driver data were used as analysis. Among the respondents, 443 (90\%) were male and 49 
(10\%) were female. The ages ranged from 19 to 78 years old. The average age was 42.67 years $(S D=15.19)$, and the average driving experience was 13.42 years $(S D=9.24)$.

\section{Materials}

\section{Driving Stress Scale (DSS)}

To measure the stress that arises while driving, this study used the 38 questions of Driving Stress Scale (DSS) questions developed by Lee and Lee (2008). Driving stress measurement consists of five factors: progress obstacle (e.g. "Suddenly, when the bus breaks out of its lane"), driving circumstances (e.g. "When you drive onto a slippery road"), accident \& regulation (e.g. "Suddenly, when the vehicle in front stops"), regulation observance (e.g. "No vehicles on the road when you wait for the green light to appear"), and time pressure (e.g. "When you should make a wise and timely decision for maneuvers"). The questions of the Driving Stress Scale are divided into the Driving Stress Intensity (DSI) evaluation and the Driving Stress Frequency (DSF) evaluation (for the previous year). Participants rated the extent to which each item described their feelings in close relationships on as 5-point scale ranging from (1) "not at all to" (5) "very much".

The score for each question of the DSQ is the multiplied value of each question's score for both DSI and DSF. Therefore, each question's
DSQ minimum score is 1 and the maximum score is 25. A reliability figure on the Cronbach's alpha coefficient was high for the driving stress scale which is .95 in the study of Lee and Lee (2008) with Cronbach's alpha coefficient scale being .96 in the current study. A reliability figure of the sub-components on the Cronbach's alpha scale appeared as follows: progress obstacle result, .93, driving circumstance, .90, accident \& regulation .85, traffic rules, .87 and time pressure, .80 .

On this basis, one score was computed by averaging the items on the scale. A principal component's analysis yielded a single factor with eigenvalue greater than 1.0 which accounted for 59 percent of the variance in the items.

\section{Driving Stress Coping Behavior Scale} (DS-CBS)

To measure the Driving Stress Coping Behavior, this study used the Driving Stress Coping Behavior Scale (DS-CBS)'s 24 questions developed by Lee and Lee (2009a). The DS-CBS's score was divided into two factors: good coping behavior (e.g. "I try to keep all traffic laws") and bad coping behavior (e.g. "If I do not have enough time to be speeding"). Participants rated the extent to which each item described their feelings in close relationships on as 5-point scale ranging from (1) being "not at all to (5) being "very much".

The minimum score of each factor's 12 questions was 12 points and the highest score 
was 60 points. A reliability figure on the Cronbach's alpha scale resulted in .76 based from Lee \& Lee (2009) and .79 in this study. A reliability figure of sub-components on Cronbach's alpha scale appeared as follows: safety driving resulting in .88; comfort driving, .76; violence driving; .87 , regulation offence, .78.

On this basis, one score was computed by averaging the items on the scale. A principal component's analysis yielded a single factor withe given value which is greater than 1.0 which accounted 52\% for good coping and 56\% for bad coping in the variance in the items.

\section{Traffic Accident Risk Index (TARI)}

To measure the rate of drivers' traffic accident risks, Traffic Accident Risk Index (TARI) was used (Lee, Lee, \& Song, 2009). It questioned how many accidents were experienced during the previous year either as the suspect of the assault or the injured party. The added value of all the questions' scores came up with the TARI score, and the bigger the value became, the higher the traffic accidents risk rose. Participants rated the extent to which each item described their feelings in close relationships on a rate of 5-point scale ranging from (1) being "not at all" to (5) being "very much". The minimum sum score of each question is 6 points each therefore the maximum sum score is to result in 30 points.

A reliability figure on Cronbach's alpha scale ended up with a result of .88 in this study. A reliability figure of sub-components on Cronbach's alpha scale appeared as follows: near accident being, .79, ambient anxiety, .88, self anxiety, .88.

\section{Speed Desire Frustration Questionnaire (SDFQ)}

To check the level of the drivers' speed desire frustration, we applied the Speed Desire Frustration Questionnaire, short for SDFQ (Lee \& Lee, 2009b). This method helped modify questions from the Inclination to Speed Index of Stradling, Meadows, and Beatty (1999, 2004). SDFQ consists of eight questions in two forms. A "reliability" figure on the Cronbach's alpha scale, which resulted in .86 from the conducted data gathering procedure. A reliability figure of sub-components on the Cronbach's alpha scale appeared as follows: normal speed being .74, and preferred speed, .86 .

\section{Analysis method}

For data analysis of this study, the SPSS 16.0 was used. Detailed analysis procedures are as follows: Above all, to verify a controlling effect, the proponents evaluated the difference between path coefficient values when speed desire frustration was input as a controlling variable into mediate models of driving stress, coping behavior and traffic accident risks.

First, the descriptive statistics were done for the demographic characteristics of the subjects 
that did not require inferential statistics.

Second, for verification of this study proposal, Structural Equation Modeling (SEM) was conducted. SEM is the most efficient and least problematic method of testing moderating effects. By controlling for measurement error, SEM avoids problems that prevented underestimation of moderating effects. It also permitted estimation of models that include multiple mediators (e.g. Shadish \& Sweeney, 1991). The SEM analyses were conducted using the AMOS 5.0 program, on the basis of the maximum likelihood estimation procedure. The analysis of the proposed moderation model followed the two-step approach recommended by Baron and Kenny (1986).

Establishment of a measurement model is achieved by statistically significant loadings, as well as an acceptable model fit. The commonly used chi-square index that was developed by Satorra and Bentler (1988) is reported for reasons being completeness, but was not consulted for low-n analyses because of its extreme sensitivity to sample sizes. However, we used the chi-square difference test in the comparison of models. We used four indexes to assess the goodness of it of the measurement and models: Tucker-Lewis index (TLI; values higher than .90 represent accept able model fit), the comparative fit index (CFI; values higher than .90 represent accept able model fit), the root-mean-square error of approximation (RMSEA; values lower than 1.00 represent accept able model fit), and the expected cross-validation index (ECVI; value lower than another model represent acceptable). Chi-square difference between models were verified with the critical value of .10 and .05 about the degree of freedom.

\section{Results}

\section{Preliminary Analysis and Descriptive Statistics}

To check for normality of distribution, the mean, standard deviation of observed variables were examined (see Appendix). In general, the score from this sample can be characterized as having normal distribution.

The correlation of observed variables was examined among the components of Driving Stress Scale (DSS), Driving Stress-Coping Behavior Scale (DS-CBS), Traffic Accident Risk Index (TARI), and Speed Desire Frustration Questionnaire (SDFQ).

Each of the components of DSS showed significant positive correlation to each other $(r=$ $.59 \sim .89, p<.001)$. The DSS tended to show negative correlation with the Good Coping Behavior Scale $(r=-.04 \sim-.09, p<.05)$, while it tended to show positive correlation with the Bad Coping Behavior Scale $(r=.11 \sim .27, \quad p<.05$ .001). Furthermore, each component of DSS showed positive correlation with the components 
of TARI $(r=.12 \sim .22, p<.01 \sim .001)$. It tended to show positive correlation with the components of SDFQ $(r=.09 \sim .20, p<.05 \sim .001)$

Each of the components of DS-CBS showed significant correlation $(r=-.42 \sim-.94, p<.001)$. Components of Bad Coping Behavior Scale resulted to have positive correlation with the components of TARI $(r=.11 \sim .20, p<.05 \sim .001)$. The components of Good Coping Behavior Scale tended to show negative correlation with each component of DS-CBS $(r=-.18 \sim-.09, p<.05$ .001). Each component of Good Coping Behavior Scale showed positive correlation with each component of SDFQ $(r=.10 \sim .34, p<.05$ $\sim$.001).

Each of the components of TARI showed significant positive correlation to each other $(r=.40 \sim .88, p<.001)$. Each of the components of SDFQ also showed significant positive correlation to each other $(r=.33 \sim .73, p<.001)$.

Verifying the Controlling Effect of Speed Desire Frustration on the Influence of Driving Stress and a Coping Behavior Pattern with Traffic Accident Risk.

To verify the controlling effect of speed desire frustration on the influence of driving stress and a coping behavior pattern with traffic accidents risks, we analyzed the controlling effect. For this, we divided drivers into two groups: one group consisted of the drivers who had higher speed desire frustration score $(N=214)$ than the average 22.03 score $(S D=17.78)$, and the other group consisted of the drivers who had a lower speed desire frustration score $(N=278)$ than the average. We used the structure invariance verification method as a verifying method of the controlling effect to determine whether there is a significant difference between these two groups in terms of a path coefficient based on the structure model. The basic hypothesis to verify the structure invariance is the sufficiency of the form configural and Metric invariance.

\section{Configural Invariance Verification}

Configural invariance refers to the hypothesis which proposes that the most suitable model statistically needs to be identically suitable to the group of comparison. The proponents can tell that Configural invariance becomes valid if both groups show good suitability, when the groups according to the levels of speed desire frustration are divided.

The high speed desire frustration group's TLI appeared .90, CFI .93 and RMSEA .09 according to the analysis of suitability on part

Table 1. Configural Invariance

\begin{tabular}{ccccccc}
\hline Model fit & $\mathrm{X}^{2}$ & $d f$ & $\mathrm{P}$ & TLI & CFI & RMSEA \\
\hline High SDFQ & 112.82 & 37 & .00 & .90 & .93 & .09 \\
\hline Low SDFQ & 71.65 & 37 & .00 & .96 & .98 & .06 \\
\hline
\end{tabular}


mediate model. The low speed desire frustration group's model suitability index was TLI .96, CFI .98, RMSEA .06. Both the high and the low speed desire frustration group showed good suitability indexes on the part mediate model, from which we can see that Configural invariance is valid (see Table 1).

\section{Metric Invariance Verification}

As configural invariance became valid, we verified metric invariance. The analysis of Metric invariance valuates whether each factor's figure is identical between the compared groups. Factor figures show the relation between measurement variable sand latent variables.

Therefore, the fact that factor figures are identical between the groups means the measurement variables are measuring identical latent variables. For that reason, if factor figures in the compared groups don't show a significant statistical difference, metric invariance becomes valid.

As table 2 suggests, $\mathrm{X}^{2}$ difference value of 13.13 according to the degree of freedom difference value of 8 is not statistically different from the degree of significance level. 10. Also, RMSEA value and TLI value of Metric invariance models didn't go bad as they are compared with the ones of basis model, so that Metric invariance becomes valid.

\section{Structure Invariance Verification}

As configural and metric invariance became valid, we can verify the structure invariance. The conducted comparison of path coefficients analyze models after adding invariance restriction to make the coefficients equal to the two groups according to the level of speed desire frustration.

The result of the structure invariance model comparison, which added an identification

Table 2. Metric Invariance

\begin{tabular}{|c|c|c|c|c|c|c|c|}
\hline Model fit & $x^{2}$ & $d f$ & TLI & CFI & RMSEA & ECVI & $\Delta X^{2}(8)$ \\
\hline $\begin{array}{c}\text { Configural } \\
\text { (Basic Model) }\end{array}$ & 184.51 & 74 & .93 & .96 & .06 & .81 & \\
\hline Metric & 197.64 & 82 & .94 & .96 & .05 & .80 & 13.13 \\
\hline
\end{tabular}

Table 3. Structure Invariance

\begin{tabular}{|c|c|c|c|c|c|c|c|}
\hline Model fit & $x^{2}$ & $d f$ & TLI & $\mathrm{CFI}$ & RMSEA & ECVI & $\Delta X^{2}(5)$ \\
\hline Metric & 197.64 & 82 & .94 & .96 & .05 & .80 & \\
\hline Structure & 217.21 & 87 & .94 & .96 & .06 & .82 & 19.57 \\
\hline
\end{tabular}


restriction on the metric invariance model and coefficients, was that $\Delta X^{2}(5, N=492)$ is 19.57 . On degrees of freedom 5 , the critical value of $x^{2}$ variance verifying becomes 11.07 on .05 level of significance, 9.49 on .10 , the hypothesis that the measurement structure of two groups is identical on the level of .05 was then turned down. Consequently, the proponents have made sure that a controlling effect occurs according to the speed desire frustration level in the mediator model, in which driving stress and a coping behavior pattern (good or bad) has an influence on traffic accidents risks (see Table 3).

Table 4 and Figure 1 shows the difference of path figures. Concretely, the high speed desire frustration driver-group's path of direct effects on traffic accident risks showed a statistical significance $(\beta=.54, p<.001)$. An influence on bad coping behavior of driving stress also showed a statistical significance $(\beta=.16, p<.05)$. For the lower speed desire frustration drivers, only the influence on traffic accidents risks of bad coping behavior had a statistical significance $(\beta=.25, p<.01)$.

Table 4. Path Figures on Speed Desire Frustration Level

\begin{tabular}{ccc}
\hline Path & High SDFQ & Low SDFQ \\
\hline DSS $\rightarrow$ TARI & $.09(.54) * * *$ & $.01(.03)$ \\
DSS $\rightarrow$ GC & $-.02(-.09)$ & $-.01(-.04)$ \\
DSS $\rightarrow$ BC & $.04(.16)^{*}$ & $.03(.07)$ \\
GC $\rightarrow$ TARI & $-.02(-.02)$ & $.12(.16)$ \\
BC $\rightarrow$ TARI & $.13(.18)$ & $.13(.25)^{* *}$ \\
\hline
\end{tabular}

Note: High $(N=214)$, Low $(N=278)$; Major weights are regression weight, $(\quad)$ are standardized regression weights. $* * * p<.001, * * p<.01, * p<.05$
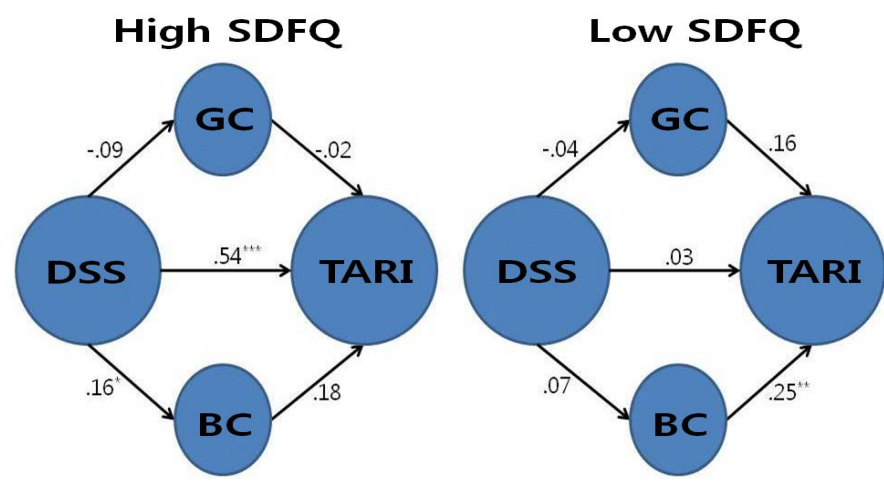

Figure 1. The structural model

Note: High $(N=214)$, Low $(N=278) ; * * * p<.001, * * p<.01, * p<.05$ 


\section{Discussion}

This study was fulfilled in order to be able to know whether a driver's speed desire frustration plays a controlling function in the mediator model, where driving stress influences traffic accident risks through coping behavioral patterns.

After verifying the moderating effect, a significant controlling effect on speed desire frustration levels was confirmed in the mediator model, where driving stress helps manage the prevention of traffic accidents through coping behavioral patterns. Concretely, high speed desire frustration group's path of direct effects on traffic accident risks, have shown a statistical significance. When the speed desire frustration was involved as a controlling variable, direct path figure value of high speed desire frustration driver's driving stress influencing traffic accidents risks was $\beta=.54$. This result confirmed that speed desire frustration is the controlling variable, which allows driving stress to prevent traffic accident risks significantly. As for the lower speed desire frustrated group, either a director, an indirect effect of driving stress on traffic accident risks did not show a statistical significance. Only the path of bad coping behavior increasing traffic accident risks showed significance. This suggests that if the driver has a violent or a traffic-rule-breaking driving behavior habitually in spite of lower speed desire frustration, traffic accident risks go high.
Summarizing all the results regarding speed desire frustration, one can see that in the highly speed desire frustrated drivers' group, driving stress directly influences traffic accident risks, while in the lower speed desire frustrated drivers' group, stress driving does not have either a direct or an indirect effect on traffic accident risks.

In other words, driving stress can function as a significant variable on traffic accident risks according to the speed desire frustration level or not. Therefore, it is clear that in order to reduce the negative influence of driving stress on traffic accident risks, decreasing a driver's speed desire frustration level is the primary task.

Being aware of the risks of speed desire and being familiar with the effective driving education system can help minimize speed desire frustration. Since, developed countries have greatly affected societies through and educational program for aspiring drivers.

The present study was conducted to determine the moderating effect of speed desire frustration on the relationship between driving stress and coping behavior on traffic accident risks. As a result, a driver's speed desire frustration level played a control role in the relation between driving stress, coping behavioral patterns and traffic accident risks. However, when the speed desire frustration is perceived as a moderating variable, the direct path, which is referred to as the impact of driving stress on the traffic accident, is statistically significant, while the 
indirect path that the traffic accident risk is affected by the driving stress through coping behavioral patterns are found to be statistically insignificant. This significant reduction in the path of the driver population level phenomena which is done by separating the whole number of cases that have been revealed to be biased because they shrink parameter estimates.

Therefore a need for research about the adjusting factor from the coping behavioral pattern that can significantly regulate indirect mediating routes influenced by traffic accident risks from the driving stress must be performed.

Besides, the portion of women drivers among the drivers group is only 10 percent in this research. The fact that women drivers take up to 40 percent of all drivers, makes this unbalanced gender ratio a limitation in explaining the study's outcome. Hence, the appropriate ratio of men and women drivers should be sampled in future researches to be conducted to reflect the actual gender ratio.

The driving stress caused by the speed desire frustration that negatively affects traffic accident risks are found in this study as a main highlight. However, the variable that regulates for the driving stress and coping behavioral pattern to reduce the traffic accident risks may exist. In further researches to be done in the future, the proponents of these futures studies should examine the variable that is thought to positively change the impact of the driving stress and coping behavioral pattern to the risks.
This study verified whether a driver's speed desire frustration plays a control role in the relations between driving stress and traffic accident. As a result, a driver's speed desire frustration level played a huge role in the relation between driving stress and traffic accident risks. This indicates that a driver's speed desire frustration level changes driving stress sensitivities, thus changing the effects of selecting coping behavior types and causing differences in total traffic accident risks. The results show that the mere concentration on driving stress management cannot sufficiently lower the risks for traffic accidents caused by driving stress. This is because driving stress has indirect influences on traffic accidents. Hence, it will be necessary to seek how to reduce driving stress and control coping behavior types in order to lower the traffic accidents by the stress levels. In addition, it will be indispensible to seek how to reduce a driver's speed desire frustration level, since speed desire frustration negatively strengthens the relation between driving stress and traffic accident risks. The reduction of traffic accidents require programs to help select good coping behaviors as well as to manage driving stress.

\section{References}

Beron, R. M., \& Kenny, D. A. (1986). The moderator-mediator variable distinction in 
social psychological research: Conceptual, strategic, and statistical considerations. Journal of Personality and Social Psychology, 51, 1173-1182.

Berkowitz, L., \& Lepage, A. (1967). Weapons as aggression-eliciting stimuli. Journal of Personality and Social Psychology, 7, 202-207.

Block, J., \& Kremen, A. M. (1996). IQ and ego-resiliency: Conceptual and empirical connections and separateness. Journal of Personality and Social Psychology, 70(2), 349361.

Cooper, P. J. (1996). The relationship between speeding behaviour (as measured by violation convictions) and crash involvement. Journal of Safety Research, 28(2), 83-95.

Desmond, P. A., Matthews, G, \& Bush, J. (2001). Individual differences in fatigue and stress states in two field studies of driving. Proceedings of the Human Factors and Ergonomics Society 45th Annual Meeting, 1571- 1575.

Hoare, P. N. (2001). Stress traits and coping styles as predictors of stress symptoms in bus driver. University of Southern Queensland. Australia.

Kontogiannis, T. (2006). Patterns of driver stress and coping strategies in a Greek sample and their relationship to aberrant behaviors and traffic accidents. Accident Analysis and Prevention, 38, 913-924.

Korea Road Traffic Authority (1998). A package of measures for the overspeed prevention.

Lazarus, R., \& Folkman, S. (1986). Stress and adaptational outcomes: The problem of confounded measures. American Psychologist, 40(7), 770-779.
Lazarus, R., \& Folkman, S., (1991). Coping and emotion. In A. Monat \& Lazarus(Eds.), Stress and coping: An anthology (pp.207-227). New York: Columbia University.

Lee, S. Y., \& Lee, S. C. (2008). Validation and Development of the Driving Stress Scale. Korean Journal of Psychological and Social Issues, 14(3), 21-40.

Lee, S. Y., \& Lee, S. C. (2009a). The change of traffic accident risk degree by driving stress coping patterns. Korean Journal of Psychological and Social Issues, 15(3), 431-446.

Lee, S. Y., \& Lee, S. C. (2009b). The influences of Speed desire frustration on Driving Stress. Korean Journal of Psychological and Social Issues, 15(2), 319-338.

Lee, S. Y., \& Lee, S. C. (2010). A validation study and confirmatory factor analysis of the traffic accident risk index. Korean Journal of Industrial and Organizational Psychology, 23(1), 75-87.

Lee, S. Y., Lee, S. C., \& Song, H.W. (2009). Confirmatory factor analysis of the Traffic Accident Risk Index(TARI). International Conference on Asia Pacific Psychology (ICAPP), 207-208.

Parker, D., Reason, J. T., \& Manstead, A. S. R. (1995). Behavioral characteristics and involvement in different types of traffic accident. Accident Analysis and Prevention, 27, 571-581.

Rumar, K. (1985). The role of perceptual and cognitive filters in observed behavior. In Evans, L., Schwing, R. C., editors, Human Behavior and Traffic Safety, New York, NY: Plenum Press, pp.151-165. 
Satorra, A., \& Bentler, P. M. (1988). Scaling corrections for chi-square statistics in covariance structure analysis. In American Statistical Association 1988 Proceedings of the Business and economic section (pp.308-313). Alexandria, VA: American Statistical Association.

Shadish, W. R., \& Sweeney, R. (1991). Mediators and moderators in meta-analysis: There's a reason we don't let dodo birds tell us which psychotherapies should have prizes. Journal of Consulting and Clinical Psychology, 59, 883-893.

Stradling, S. G., Meadows, M. L., \& Beatty, S. (1999). Factors affecting car use choices. Transport Research Institute. Napier University: UK.

Stradling, S. G., Meadows, M. L., \& Beatty, S. (2004). Characteristics and crash-involvement of seeding, violating and thrill-seeking drivers. Traffic and Transport Psychology Proceedings of the ICTTP 2000, 177-192.
Underwood, G., Chapman, P., Wright, S., \& Crundall, D. (1999). Anger While driving. Transportation Research, PartF, 2, 55-68.

Westeman, S. J., \& Haigney, D. (2000). Individual differences in driver stress, error and violation. Personality and Individual Differences, 29, 991-998.

Williams, A., Kyrychenko, S., \& Retting, R. (2006). Characteristics of speeders. Journal of Safety Research, 37, 227-232.

1 차원고접수 : 2012. 6. 8 수정원고접수 : 2012. 7. 20 최종게재결정 : 2012. 8. 1 


\title{
운전스트레스와 대처행동 양식이 교통사고 위험에 미치는 영향에서 속도욕구좌절의 조절효과
}

\author{
이 순 열 \\ 이 순 철 \\ 도로교통공단 \\ 충북대학교 심리학과
}

\begin{abstract}
본 연구는 운전스트레스와 대처행동 양식이 교통사고 위험에 미치는 영향에서 속도욕구좌절 의 조절효과를 알아보고자 실시되었다. 연구결과, 운전스트레스와 대처행동 양식이 교통사고 위험에 영향을 미치는 관계에서 운전자의 속도옥구좌절 수준은 조절적 역할을 하고 있었다. 운전자가 느끼는 속도에 대한 욕구좌절감 수준에 따라서 운전스트레스의 민감도가 변화되었 다. 또한, 운전스트레스 민감도의 변화가 운전스트레스가 순행적 대처행동과 역행적 대처행 동에 영향을 미치는 강도를 변화시키는 것을 확인하였다. 나아가 속도욕구좌절 수준에 따른 운전스트레스 대처행동 양식의 변화는 교통사고 위험에서 차이를 발생시키는 것을 검증하였 다. 종합하여 보면, 운전자가 속도에 대한 욕구좌절감을 많이 느끼게 되면 운전스트레스와 대처행동 양식이 교통사고 위험을 증가시키는 영향을 높이게 된다는 것이다. 본 연구 결과 는 운전자의 속도에 대한 욕구좌절 수준을 감소시키는 것이 운전스트레스의 부정적 영향과 교통사고 위험을 줄일 수 있는 해법이 됨을 시사한다.
\end{abstract}

주요어 : 운전스트레스, 대처행동, 교통사고 위험, 속도욕구좌절 


\section{$\langle$ Appendix〉}

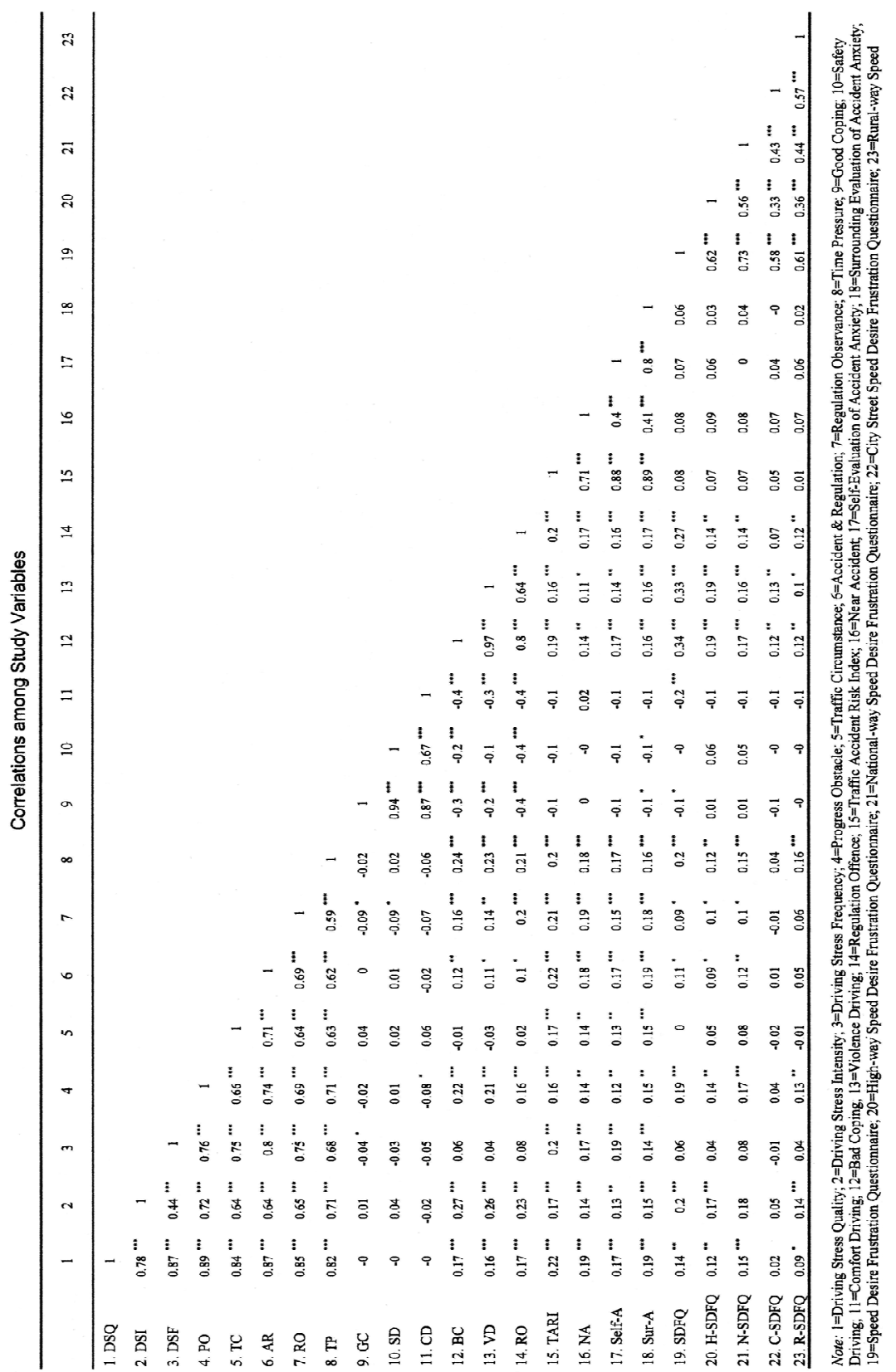

